\title{
Ocular Bungee Cord Injury: Case-Report and Literature Review
}

\author{
Jessica Ruel-Laliberté ${ }^{1}$, Louis Morin ${ }^{1}$, Alice Turcot $^{2 *}$ and Patricia Ann Laughrea ${ }^{3}$ \\ ${ }^{1}$ Université Laval Faculté de Médecine, Canada \\ 2Institut National De Santé Publique Du Québec, Canada \\ ${ }^{3}$ Centre Hospitalier De L'université Laval, Canada
}

*Corresponding author: Dr. Alice Turcot, Institut National De Santé Publique Du Québec, 945, Avenue Wolfe, Québec, Qc, G1V 5B3, Canada, Tel: 418-650-5115-(5207)

\begin{abstract}
A 27-year-old female patient sustained a left eye injury while manipulating a hook end bungee-type elastic cord. She suffered from severe anterior and posterior segments ocular trauma that required two surgeries and left her with permanent sequelae. The aim of this paper is to present a literature review on ocular trauma associated with bungee cords.
\end{abstract}

\section{Case-Report}

On December $7^{\text {th }} 2012$, a 27-year-old female patient was injured in the left eye in the context of her work. While she was transporting a trolley on which were stacked boxes of documents, a bungee-type elastic cord broke off and bit her left eye. She was transported to the Emergency Room where an ophthalmologist diagnosed a left peri-ocular contusion and hyphema.

Ten days after the initial injury, the patient showed little improvement in her symptoms. At this second visit, the patient was diagnosed with a traumatic cataract and macular oedema (Figure 1).

Six weeks post-trauma, visual acuity (VA) improvement was minimal, mydriasis persisted and a choroidal rupture was seen on fundus fluorescein angiography.

She underwent surgery on May $13^{\text {th }} 2013$ to remove the traumatic cataract, combined with intraocular lens implantation.

Six months after the trauma, the optical result was considered good, but the patient still suffered from significant photophobia. A left pupilloplasty was done in order to reduce photophobia.

Post-operatively, the aesthetic result was good, photophobia was diminished and VA increased to 20/70 (6/21).

The patient remained with permanent functional visual limitation, decrease of her visual acuity and photophobia. This resulted in a limitation in certain activities such as driving a car and working for long hours under inappropriate lighting. She had to use appropriate tools such as an adapted computer and tailored glasses to improve her ability to function properly.

\section{Discussion}

\section{Literature review}

According to literature data, traumas to the eye caused by elastic bungee cords are often very severe [1-4]. Patients may present with trauma to the anterior and posterior segments of the eye. The release of these elastics causes high velocity missile injuries to the eyes, with a maximum potential velocity of $74.3 \mathrm{~m} / \mathrm{s}$ and a maximum transmittable energy of $60.7 \mathrm{~J}$ (Litoil and Catalano) [1,2,4-6]. The hyphema is a common condition with this type of injury from the violent release of the elastic against the eye. An hyphema is defined by the presence of blood in the anterior chamber of the eye. Macular oedema is a potential sequela of trauma of the posterior segment of the eye, frequently associated with choroid rupture [7]. Aldave, et al. reported a series of 67 patients treated for ocular trauma caused by bungee cords. The most common injuries were hyphema $(63 \%)$, commotio retinae $(55 \%)$ and eyelid 


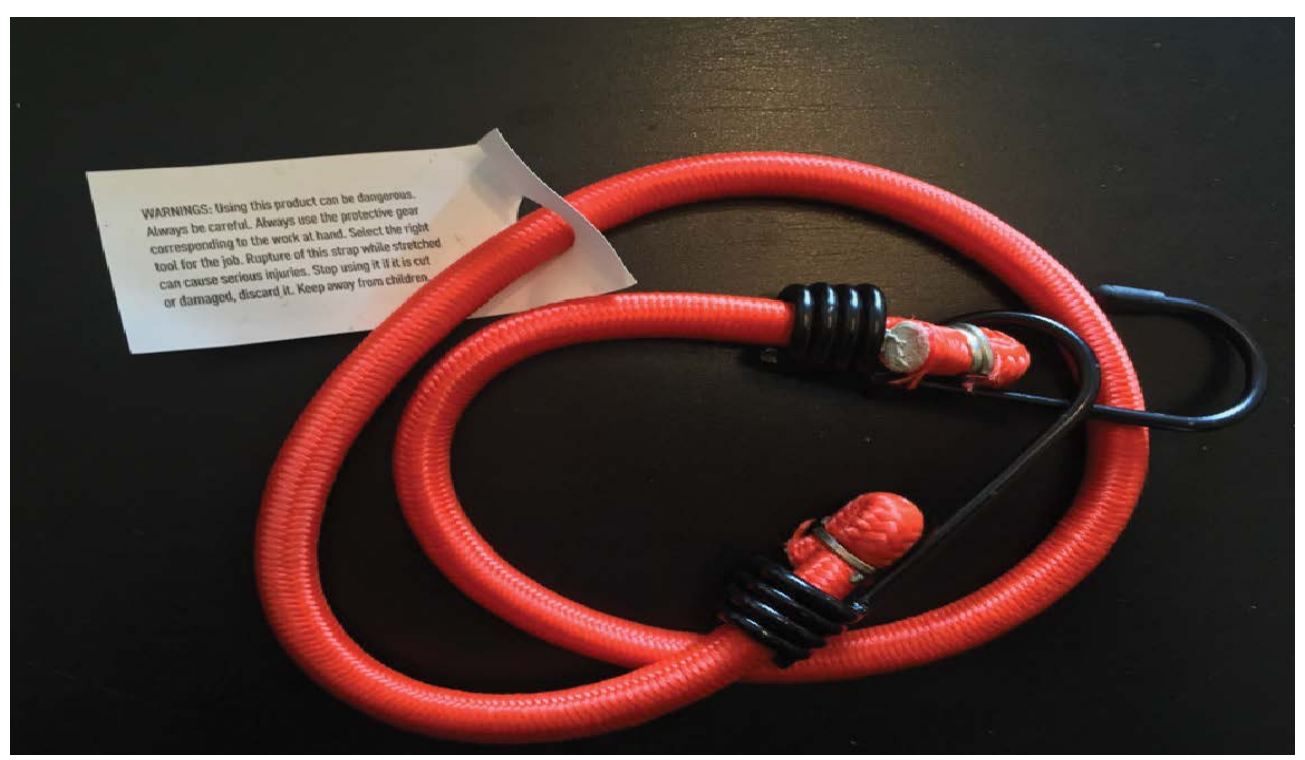

Figure 1: Red bungee cord strap with reverse hook. Source: Ruel-Laliberté, 2016.

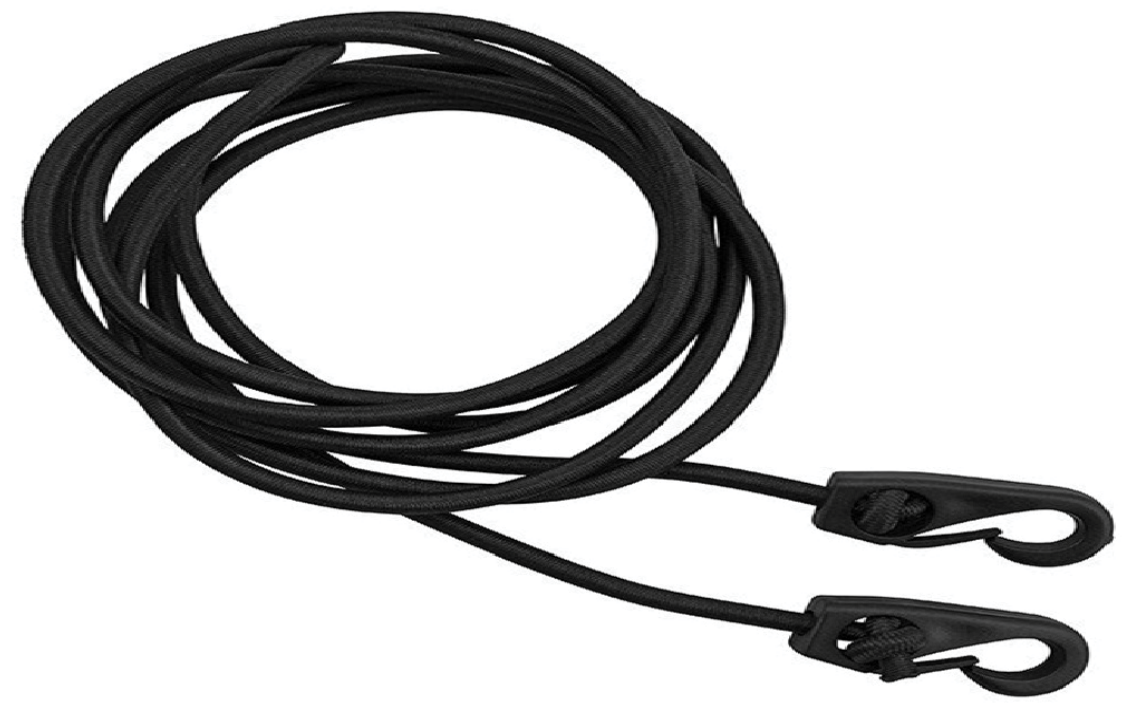

Figure 2: 90" Bungee cord with hooks. Source: [9].

oedema (60\%). Thirty-one percent of these subjects eventually required a surgery [2].

The case presented here was a patient with injuries to anterior and posterior segments of the eye. The patient developed a traumatic cataract [8], for which she needed surgery. The patient had a sphincter ruptures that eventually required pupilloplasty. She also presented a choroidal rupture and was left with permanent functional and visual sequelae.

\section{Prevention}

In Canada, manufacturers of bungee cords notify the clients on their packaging regarding the risks associated with the use of their products. From our point of view, warnings included on the bungee cords packages aren't explicit enough. We believe that national campaigns should be conducted to adequately inform users of this product of the risks associated with its use, preferably during the summer period, when the use of these cords is at its peak (moving, sailing, camping). We think that manufacturers should be encouraged to clearly write and add pictures on the package concerning the risk of high velocity trauma associated with the use of these cords, particularly when they are stretched. We also believe that manufacturers could modify the hook ends to make them safer. Some authors [9] proposed to replace the "S" and "J" "J"-shaped hooks with a gated clip, thus reducing the risk of unintentional hook release $[2,5]$. A reduction in the number of bungee cords injuries will happen only when the industry will be more aware of the devastating injuries caused by their cords and will decide to take actions to prevent them (Figure 2).

\section{References}

1. Agrawal R, Shah M, Mireskandari K, Yong GK (2013) Controversies in ocular trauma classification and management: Review. Int Ophthalmol 33: 435-445.

2. Aldave AJ, Gertner GS, Davis GH, Regillo CD, Jeffers 
JB (2001) Bungee cord-associated ocular trauma. Ophthalmology 108: 788-792.

3. Brouzas D, Charakidas A, Papagiannakopoulos D, Koukoulomatis P (2003) Elastic cord-induced ocular injuries. Injury 34: 323-326.

4. Chorich LJ 3rd, Davidorf FH, Chambers RB, Weber PA (1998) Bungee cord-associated ocular injuries. Am J Ophthalmol 125: 270-272.

5. Hollander DA, Aldave AJ (2002) Ocular bungee cord injuries. Curr Opin Ophthalmol 13: 167-170.
6. Litoff D, Catalano RA (1991) Ocular injuries caused by elastic cords. Arch Ophthalmol 109: 1490-1491.

7. Simanjuntak GW, Wijaya J, Hasibuan H (2012) Management of traumatic hyphema with anterior chamber maintainer. Semin Ophthalmol 27: 8-10.

8. Shah M, Shah S, Upadhyay P, Agrawal R (2013) Controversies in traumatic cataract classification and management: A review. Can J Ophthalmol 48: 251-258.

9. http://vibekayaks.com/products/bungee-lashing-jhooks? variant $=6908014595$ 